\title{
Mammary lipofiling seen to the hospital complex of Dax
}

\author{
Rainibarijaona Lanto Nirina Aimé1, Rakotonirina Andriamaro Martial ${ }^{2 *}$, \\ Rakotoarivony Valerie Kamary ${ }^{2}$, Andriamihajason Lova ${ }^{2}$, Housni Ibrahim ${ }^{2}$, Eric Rousseau ${ }^{3}$, \\ Hery Rakotovao Andrianampanalinarivo ${ }^{2}$
}

\author{
${ }^{1}$ Department of Obstetrics and Gynecology, Soavinandriana Hopital Center, Antananarivo, Madagascar \\ ${ }^{2}$ Department of Obstetrics and Gynecology, Befelatanana University Hospital Centre of Obstetric Gynecology in \\ Antananarivo, Madagascar \\ ${ }^{3}$ Department of Obstetrics and Gynecology, Dax Hospital Centre of Obstetric Gynecology Bordeaux, France
}

Received: 17 December 2018

Accepted: 11 March 2019

\section{*Correspondence:}

Dr. Rakotonirina Andriamaro Martial,

E-mail: andriamarorakotonirina@gmail.com

Copyright: () the author(s), publisher and licensee Medip Academy. This is an open-access article distributed under the terms of the Creative Commons Attribution Non-Commercial License, which permits unrestricted non-commercial use, distribution, and reproduction in any medium, provided the original work is properly cited.

\section{ABSTRACT}

Background: Taken care therapeutics of breast cancer is in constant evolution. She links, according to the stadium of illness, a specific treatment of the cancer and mammary reconstruction which makes integral part of the treatment of breast cancer today. The lipofilling or lipostructure is one of the techniques used in mammary reconstruction.

Methods: A descriptive retrospective study on lipofilling accomplished in Hospital complex of Dax, France from January $1^{\text {st }}$, 2016 till October $31^{\text {st }}$, 2017 was accomplished, to assess the rate of aesthetic and psychological satisfaction of the patients on the basis of breast $\mathrm{Q}$, then to assess its effectiveness and its security. The statistical analysis was made with the software Excel of Microsoft Office 2007.

Results: Authors could record 52 lipofillings at 40 patients among 1212 gynecological surgical operations is $4.29 \%$ surgical activities. 47 cases (90.38\%) of lipofilling were accomplished at 35 patients after a surgery for breast cancer accomplishing a frequency of $3.87 \%$ of surgical activity. The women from 49 to 54 years old are the most concerned the median age of which was of 52 years ( 37 and 73 years) and the patients are still sexually active in 26 cases (74.29\%). The mastectomy was practiced in 32 cases $(91.45 \%)$. An immediate reconstruction was accomplished at 29 (82.86\%) patients. The back big rag autologous was used in 22 cases (62.85\%). In 33 cases (94.27\%), the lipofilling was accomplished to supplement the reconstruction among which by the back big rag at 22 patients $(62.5 \%)$ and by mammary prosthesis at 11 patients $(31.42 \%)$. One took a sample in 32 cases of a volume from 400 to $700 \mathrm{ml}$ of grease average of which was $456.38 \mathrm{ml}(200-800 \mathrm{ml})$. A volume from 200 to $300 \mathrm{ml}$ was injected at 17 patients (36.17\%) with an average of $264.14 \mathrm{ml}(100-600 \mathrm{ml})$. No repetition of the cancer was recorded during this study. A score of more than 60 was recorded in every domain for the valuation of satisfaction in more than $90 \%$ cases.

Conclusions: With the evolution of the taking care of the cancers of breast, mammary reconstruction by lipofilling is a technology which goes know a big development. It is a new way of natural reconstruction at the mastectomy patients who wish, more and more a less aggressive surgical gesture with good result.

Keywords: Aesthetics, Cancer, Grease, Lipofilling, Surgery

\section{INTRODUCTION}

On 100 women who die from a cancer, 25 have a breast cancer. Breast cancer is from a distance the bloodiest and most frequent cancer of the woman. In France, after 35 years, one woman of six will have a breast cancer; one of two will die from it in 5 years. The impact in France is $101 / 100000$ that is more than 53000 new cases a year. 
This impact augments by $2 \%$ a year about in all Western countries. It also augments with age passing 30/100 000 before 35 years to 400/100 000 after 65 years. In France, the mortality by breast cancer is in light reduction since 2000 (less $1.3 \%$ from 2000 till 2005). She is 35 for 100 000 women, that is about 12000 deceases by an. ${ }^{1}$ The treatment links, according to the stadium of illness, a specific treatment of the cancer and mammary reconstruction which can be immediate or secondary. Taken care therapeutics of breast cancer is in constant evolution. Current tendency is to offer treatment as conservative as possible, to limit physical, psychological and aesthetic consequences, while respecting the treatment oncologique. $^{2}$ It is supposed well that mammary reconstruction makes integral part of the treatment of breast cancer and its objective is double aesthetic and psychological. The lipofilling or lipostructure is one of the techniques used in mammary reconstruction and consists of a reinjection of autologues grease. He can be exclusive or further to and includes three stages were sample of grease, preparation or purification of grease and at the end the transfer of cloths adipeux. $^{3}$

This study aims at assessing the rate of aesthetic and psychological satisfaction of the women having benefited of lipofilling in the Hospital complex of Dax, on the basis of the questionnaire Breast $\mathrm{Q}$ and to assess effectiveness and security of this technology.

\section{METHODS}

Authors accomplished a descriptive retrospective study on lipofilling accomplished to the Hospital complex of Dax, France to assess the rate of aesthetic and psychological satisfaction, on the basis of the questionnaire Breast $\mathrm{Q}$, of women having benefited of lipofilling in mammary reconstruction after a surgery for breast cancer, and to assess effectiveness and security of this technology. Intervention was accomplished by the same surgeon.

Parameters were studied: the characteristics of the patients, the characteristics of the cancer, the holding of the lipofilling and the parameters of satisfaction of Breast Q. Recruitment is made from the computer file of the patients across which we got surgical report, the mails for the medicated doctors or gynaecologists, as well as address and telephone number of the patients. The patients were contacted for the valuation of aesthetic and psychosocial satisfaction after the lipofilling on the basis of the questionnaire Breast Q. Were include all patients having benefited from lipofilling in $\mathrm{CH}$ of Dax from January $1^{\text {st }}$, 2016 till October $31^{\text {st }}$, 2017. Were excluded from this study all patients who benefited of lipofilling for mammary reconstruction except cancérologique context, all women who did not answer questionnaires and without contact and all patients who introduced suspicious clinical and radiological anomalies after the first surgery. The satisfaction of the patients was assessed by the score of Breast Q: the more score is high, the more satisfaction is good and the upper score in 60 was considered as satisfactory.

\section{RESULTS}

During the period of study, authors could record 52 lipofillings at 40 patients among 1212 gynaecological a surgical operation is $4.29 \%$ surgical activities. 47 cases (90.38\%) of lipofilling were accomplished at 35 patients' after a surgery for breast cancer accomplishing a frequency of $3.87 \%$ of surgical activity.

Table 1: Clinical profile of the patients.

\begin{tabular}{|c|c|c|c|}
\hline Parameters & Division & $\begin{array}{l}\text { Number } \\
(\mathrm{n}=35)\end{array}$ & $\begin{array}{l}\text { Rate } \\
(\%)\end{array}$ \\
\hline \multirow{2}{*}{$\begin{array}{l}\text { Sexual } \\
\text { activity }\end{array}$} & Yes & 26 & 74.29 \\
\hline & No & 9 & 25.71 \\
\hline \multirow{3}{*}{$\begin{array}{l}\text { Antecedent } \\
\text { of lipofilling } \\
\text { before study }\end{array}$} & None & 28 & 80 \\
\hline & 1 & 1 & 2.86 \\
\hline & 2 & 6 & 17.14 \\
\hline \multirow{6}{*}{$\begin{array}{l}\text { Taken care } \\
\text { surgical }\end{array}$} & $\begin{array}{l}\text { Unilateral } \\
\text { mastectomy }\end{array}$ & 32 & 91.45 \\
\hline & Reconstruction & & \\
\hline & -Immediate & 29 & 82.86 \\
\hline & -Secondary & 6 & 17.14 \\
\hline & - Big dorsal muscle & 22 & 62.85 \\
\hline & -Prosthesis & 11 & 31.43 \\
\hline
\end{tabular}

The women from 49 to 54 years old are the most concerned the median age of which was of 52 years with extremes of 37 and 73 years (Table 1).

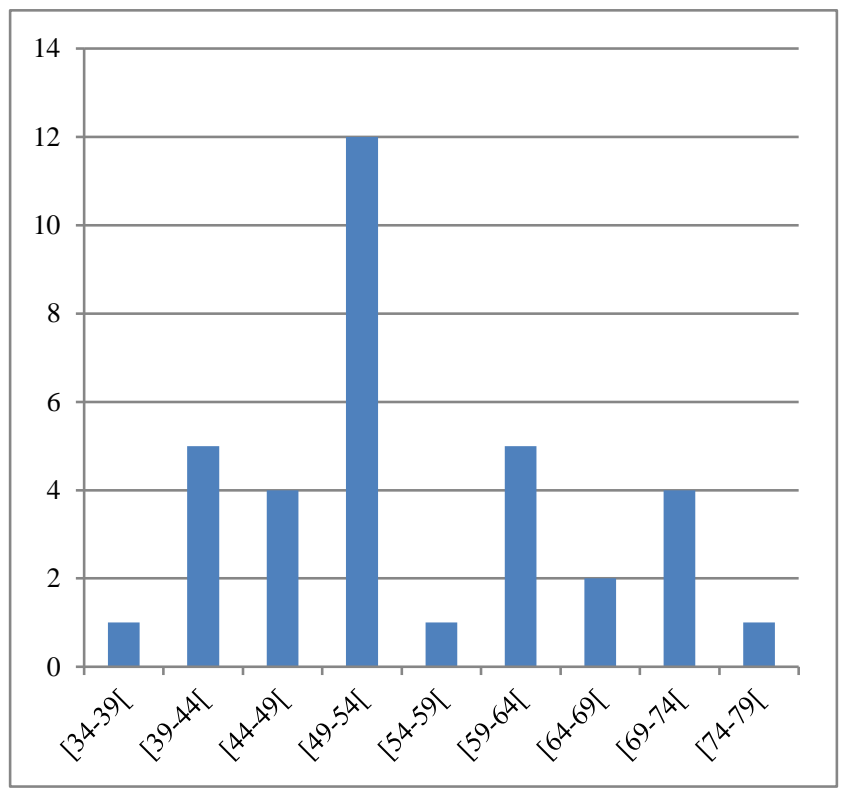

Figure 1: Sharing out of the patients according to age. 
Table 2: Concerning the lipoffiling.

\begin{tabular}{|c|c|c|c|}
\hline Parameters & Division & $\begin{array}{l}\text { Number } \\
(\mathrm{n}=35)\end{array}$ & $\begin{array}{l}\text { Rate } \\
(\%)\end{array}$ \\
\hline \multirow{22}{*}{$\begin{array}{l}\text { Holding of } \\
\text { the } \\
\text { lipofilling }\end{array}$} & \multicolumn{3}{|c|}{ Areas sampled $(n=47)$} \\
\hline & Abdomen & 19 & 40.43 \\
\hline & Thigh & 26 & 55.32 \\
\hline & Abdomen / thigh & 2 & 4.25 \\
\hline & \multicolumn{3}{|c|}{ Volumes collected $(n=47)$} \\
\hline & \multicolumn{3}{|l|}{400 to $700 \mathrm{ml}$} \\
\hline & 32 & & 68.07 \\
\hline & \multicolumn{3}{|c|}{ Purification of fats $(n=47)$} \\
\hline & Decantation & 43 & 91.49 \\
\hline & centrifugation & 4 & 8.51 \\
\hline & \multicolumn{3}{|c|}{ Injected volumes $(n=47)$} \\
\hline & 200 to $300 \mathrm{ml}$ & 17 & 36.17 \\
\hline & \multicolumn{3}{|c|}{ Duration of follow-up $(n=35)$} \\
\hline & $\geq 12$ month & 22 & 62.85 \\
\hline & \multicolumn{3}{|l|}{ Indications $(\mathrm{n}=35)$} \\
\hline & $\begin{array}{l}\text { Complement of the } \\
\text { big dorsal muscle }\end{array}$ & 22 & 62.85 \\
\hline & $\begin{array}{l}\text { Complement of the } \\
\text { prosthesis }\end{array}$ & 11 & 31.43 \\
\hline & $\begin{array}{l}\text { Sequential correction } \\
\text { of conservative } \\
\text { treatment }\end{array}$ & 2 & 5.72 \\
\hline & \multicolumn{3}{|c|}{ Number of sessions $(n=35)$} \\
\hline & 1 & 24 & 68.57 \\
\hline & 2 & 10 & 28.57 \\
\hline & 3 & 1 & 2.86 \\
\hline
\end{tabular}

The women were still sexually active in 26 cases $(74.29 \%)$ and they have never benefited of lipofilling in 28 cases $(80 \%)$. Lesion was located in the left breast in 21 cases $(60 \%)$ (Table 2$)$.

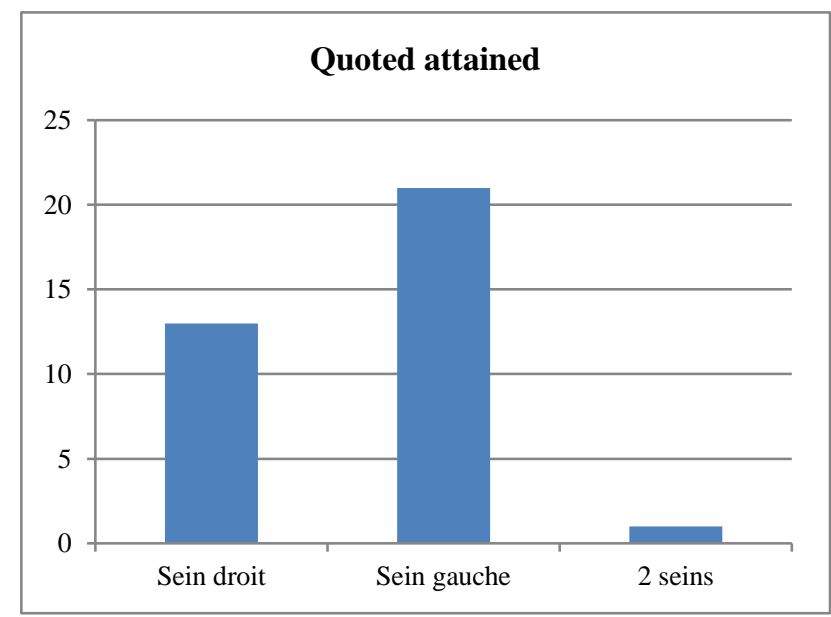

Figure 2: Sharing out of patients according to the location of lesions.

The patients benefited from a unilateral mastectomy in 32 cases $(91.45 \%)$. A surgery was accomplished at 2 patients and a bilateral mastectomy in a case. All the patients benefited a mammary reconstruction the back big rag of which immediate in 29 cases $(82.86 \%)$ and autologous was accomplished at 22 patients' $(62.85 \%)$ (Figure 1$)$.

The first session was accomplished between 6-12 months after the surgery at 17 patients $(48.57 \%)$. The medium delay between the surgery and the $1^{\text {st }}$ session of lipofilling was of 24.91 months (5-120) (Table 3).

Table 3: Satisfaction rating according to BREAST Q.

\begin{tabular}{|c|c|c|c|}
\hline Parameters & Division & $\begin{array}{l}\text { Number } \\
(\mathrm{n}=35)\end{array}$ & $\begin{array}{l}\text { Rate } \\
(\%)\end{array}$ \\
\hline \multirow{2}{*}{$\begin{array}{l}\text { Well being psycho social } \\
(\mathrm{n}=35)\end{array}$} & $<60$ & 3 & 8.57 \\
\hline & $\geq 60$ & 32 & 91.43 \\
\hline \multirow{2}{*}{ Aspect of breast $(n=35)$} & $<60$ & 4 & 11.43 \\
\hline & $\geq 60$ & 31 & 88.57 \\
\hline \multirow{2}{*}{$\begin{array}{l}\text { In comparison with } \\
\text { waitings }(n=35)\end{array}$} & $<60$ & 3 & 8.57 \\
\hline & $\geq 60$ & 32 & 91.43 \\
\hline \multirow{2}{*}{ Well be sexual $(n=26)$} & $<60$ & 4 & 15.38 \\
\hline & $\geq 60$ & 22 & 84.62 \\
\hline \multirow{2}{*}{ Well be physical $(\mathrm{n}=35)$} & $<60$ & 2 & 5.73 \\
\hline & $\geq 60$ & 33 & 94.27 \\
\hline \multirow{2}{*}{$\begin{array}{l}\text { By report has the taking } \\
\text { care }(n=35)\end{array}$} & $<60$ & 1 & 2.85 \\
\hline & $\geq 60$ & 34 & 97.15 \\
\hline
\end{tabular}

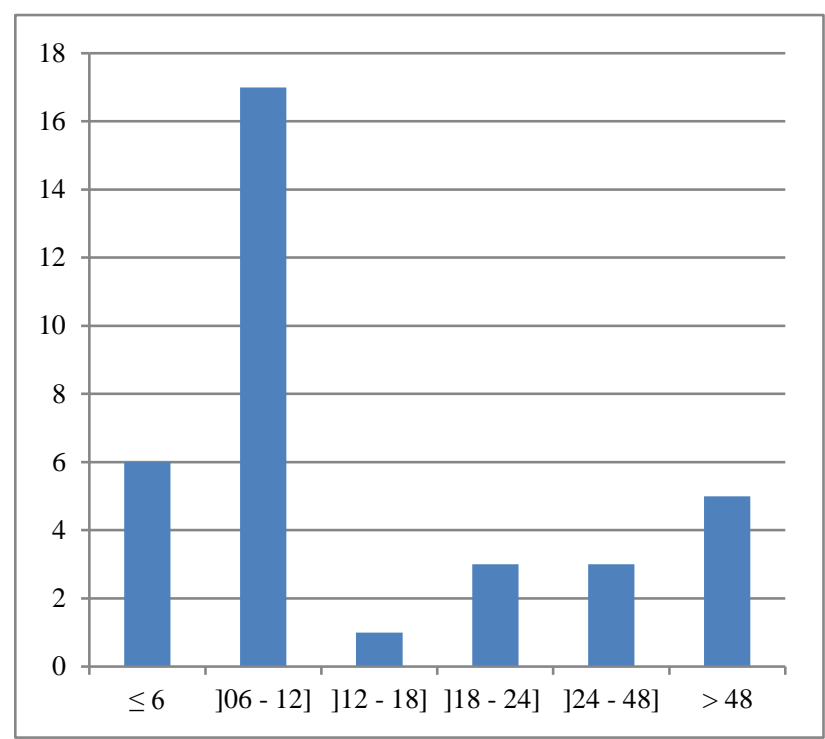

Figure 3: Sharing out of the patients according to delay between the surgery and the first session.

Sites donors were infiltrated by a physiological mixture of serum, of adrenalin and of xylocaine. One took a sample at the level of the thigh at 26 patients of grease $(55.32 \%)$. One took a sample in 32 cases of a volume from 400 to $700 \mathrm{ml}$ of grease average of which was $456.38 \mathrm{ml}(200-800 \mathrm{ml})$. The taken complete volume was $21450 \mathrm{ml}$. The purification of grease was performed by decantation in 43 cases $(91.49 \%)$. A volume from 200 to $300 \mathrm{ml}$ was injected at 17 patients $(36.17 \%)$ with an average of $264.14 \mathrm{ml}(100-600 \mathrm{ml})$. The injected 
complete volume was $12415 \mathrm{ml}$. The report between injected quantities and prewashed quantities was 0.57 .

Twenty and two patients $(62.85 \%)$ benefited more from one year of monitoring during the period of study. The medium length of monitoring was of 13.94 months (1 25 month). In 33 cases $(94.27 \%)$, the lipofilling was accomplished to supplement the reconstruction among which by the back big rag at 22 patients $(62.85 \%)$ and by mammary prosthesis at 11 patients $(31.42 \%)$. The lipofilling was only once accomplished only at 24 patients $(68.57 \%)$ during the period of study with a medium number of session in 1.34 (1-3) (Figure 2).

All the patients introduced bruises at the level of the zone of sample. A coetaneous necrosis was recorded as well as two cases of intense pain of the zone of sample $(5.72 \%)$. No repetition of the cancer was recorded during this study.

A score of more than 60 was found at $32(91.43 \%)$ patients with a very good satisfaction on psychosocial plan. Thirty-one women $(98.57 \%)$ said «be to satisfied» of them breast among which $22(62.85 \%)$ feel a good satisfaction with the upper score in 80 . Result corresponded well to waiting's of the patients in 32 cases $(91.43 \%)$. During this study, 26 patients were still sexually active. Sexual satisfaction was found at 22 patients' $(84.62 \%)$ with the upper score in 80 in 12 cases $(46.15 \%)$ while the positive impact of the lipofilling on the quality of sexual life was not confirmed at 4 patients' with a score of less than 60 . A correct and satisfactory physical activity was recorded at 33 patients' (94.28\%). Two patients $(5.72 \%)$ decided not to follow the treatment because of pain.

Almost the totality of the patients was very satisfied on the whole taking care. A patient gave a score of less than 60 because of a too long waiting in the room of transfer (Figure 3).

The statistical analysis was made with the software Excel of Microsoft Office 2007.

\section{DISCUSSION}

During our study, 52 lipofillings were practiced at 40 patients among 1212 gynaecological surgeries accomplishing a $4.29 \%$ frequency. 47 cases $(90.38 \%$ ) were accomplished at 35 patients' as part of mammary reconstruction after a surgery for cancer corresponding to a frequency of $3.87 \%$ of surgical activities during the period of study. The frequency of the lipofilling in mammary reconstruction after mammary surgery for a breast cancer varies from an author to the other one and it is less than $7 \%$ in the study of Zocchien $2017 .{ }^{4}$

In our series, the peak of frequency is between $49-54$ years with médian age of 52 years (37 à73 years) while it is of 41 years in the study of Cogliandro and of $54 \pm 13$ years old for Mundy LR in 2017 for the women who benefited from the lipofilling in mammary reconstruction after surgery for cancer of sein. ${ }^{5-6}$

The surgery that it is radical or conservative takes an important place in the treatment of breast cancer and she can go of a tumorectomy simple to one mastectomie. ${ }^{7}$

In our series, we practiced 33 complete mastectomies $(94.28 \%)$ which all benefited from a reconstruction which $29(82.86 \%)$ is immediate and $6(17.14 \%)$ are secondary. The rag of the big back autologue was used in $62.85 \%$ and reconstruction by prosthesis in $31.43 \%$. As in literature, these mastectomy are especially motivated by sprawling microcalcifications, of a big tumor, multicentrics tumors or a repetition after a treatment conservateur. ${ }^{8}$ In an American study, at the women with invasive cancers at the precocious stadium, 36\% suffered one mastectomy while $58 \%$ at the women with cancers at the advanced stadium. $42 \%$ benefited from a mammary reconstruction among which $25 \%$ immediate and $17 \%$ secondaires. ${ }^{9}$ In 2002, 77\% breast cancers benefited from a conservative treatment 8 while in our study, we had only 2 cases are $5,72 \%$ which needed a mammary reconstruction.

The first case of mammary reconstruction by autologous grease was described by Czerny in $1895 .^{3}$ This approach had been used from the beginning of the liposuccion especially following jobs of Illouz and of Fournier and technology did not cease developing since jobs of Coleman et al. ${ }^{10,11}$ All our patients had clinical balance sheets and imagery meadow and surgical post which is a precaution to take Our technology account. ${ }^{12}$ there was similar in that described in literature. After a prior analysis of the zones of sample and of reinjection, this technology includes successively: sample, preparation or purification of grease and finally transfer or reinjection of fatty cloths (face 4 in annex). ${ }^{3,10}$ Sample was performed on the thigh in $55.32 \%$ cases, on the abdomen in $40.43 \%$ cases. The choice of the site donor is based on the importance of the fatty mass and the choice of the patient. Taken zones vary from an author to the other one but generally, sample is made by taking her deep grease of stéatoméries: the abdominal region, the region trochanteric internal (jodhpurs) or the face of thighs and of knees. ${ }^{3,10,13}$ In case of weak indication of bodily mass and absence of true stéatomérie, diffuse samples can be performed, we made it that only in $4.25 \%$ of our cas. ${ }^{3}$ All interventions were accomplished under general anesthesia but authors bring back the possibility of the local anesthesia in case of small transfers for a modification to correct a defect résiduel. ${ }^{10}$ According to our habit, we infiltrate the zone to take a sample by a mixture of physiological serum, $1 \mathrm{mg}$ of adrenalin and a bottle of xylocaine.

There is no consensus concerning this mixture of seepage. Every team has its own composition. Indeed some authors use Ringer Lactate 3 and others of the 
physiological serum without there being studies established well on impact of the one or of other one on security or the effectiveness of technology. ${ }^{10-14}$ The use of xylocaine can be facultative when intervention is accomplished under anaesthesia générale, for our part we used it systematically to minimize post surgical pain as well as an antibioprophylaxy. ${ }^{14}$ Sample can be made or manually or with the aid of a pomp of aspiration by accomplishing numerous tunnels to diminish traumatisms and hemorrhages local. In our series, we have habit to take a sample with the aid of pomp of aspiration, what returns quicker procedure and at the same time allows having a lot of quantity of grease. The preparation of grease varies according to the authors and according to the habit of the surgeon. The Purification of grease can be accomplished either by centrifugation or by decantation 3-1-15 but there $\mathrm{n}$ is no net obviousness on the superiority of a method in comparison with autre. ${ }^{16}$ In this series, the preparation of the grease is accomplished by decantation in $91.49 \%$. We try at the farthest not to manipulate and not to leave the grease outside to avoid contagious risk We wash grease taken with the physiological serum then we let decant during 30 minutes while some authors recommend washing in Ringer lactate without highlighting sound avantage. ${ }^{3}$ But whatever is adopted technology, three layers are got: floating him with adipocytes abimés to be eliminated, the low part of contents which contains blood products and rubbish hématiques to eliminate also and finally the medium part containing useful grease..$^{3-15}$

The volume of grease to be taken and re-injected is also a subject of controversy but it depends especially on the volume of the mammary defect to fill up, the volume of packaging and indication: exclusive or supplementary. In our study, the lipofilling was used as a supplement to mammary reconstruction at 33 patients $(94.28 \%)$ and in exclusive in 2 cases $(5.72 \%)$. A volume of $400-500 \mathrm{ml}$ seems to be enough for a time of reconstruction mammaire, what corresponds well to our study because we could take a sample of $400-700 \mathrm{ml}$ in 32 cases $(68.07 \%)$ with a medium volume of $456.38 \mathrm{ml}(200-800$ $\mathrm{ml}$ ) and we re-injected a medium volume of $264.14 \mathrm{ml}$ $(100-600 \mathrm{ml})$ with a report between injected volume and volume taken by 0.57 , while Fabiocchi L in its study accomplished in 2017 brings back a medium injected volume $318.05 \mathrm{ml}$ on $640 \mathrm{ml}$ of medium volume taken with a medium number of session of $3,6 .{ }^{17}$ Bayti $\mathrm{T}$ transferred a medium volume of $1421.2 \mathrm{ml}$ with a medium number of session of 4,9 during an exclusive lipomodelage and in additive of a technology or of a conservative surgery, the transferred medium volume was $212.2 \mathrm{ml}$ and the medium number of session was $1,4 .{ }^{13}$ Other authors bring back quantities less important in the same conditions. ${ }^{5,14,18}$ Of our part, $68.57 \%$ patients had one session only with a medium number of 1.34 sessions (1-3) and 6 women (17.14\%) have already had 2 sessions before study. We decide on a new session according to the result of the previous session and the wish of the patient. The number of session varies according to the volume of the mammary defect to correct and from an author to the other one 14.19 but generally, 3 or 4 injections are enough for a mammary reconstruction complète. ${ }^{3}$ La mammary reconstruction by lipofilling is a simple technology, not much invasive, without scar with rare complications. Technology is efficient especially for the correction of the internal part and of the superointernal quadrant of sein. ${ }^{3}$ As in literature, all our patients introduced pain in the sites of sample and in the breast during first 48 hours of the surgical post but which give classical up well with sedative analgesic.

We also noticed at all our patients' of bruises in the breast who disappear at the end of 15 days, of edemata of the site donor which are thoroughly reduced in 3 months. ${ }^{10-14}$ Some authors recommend the seepage of ropivacaine to limit pain and automassage to speed up the resorption of the edemata 14 which we did not accomplish. The edemata of the breast are reduced at the end of 1 month 10 , it is that we also determined at our patients'. Other complications can happen. Van Turnhout AA and al recorded $1.8 \%$ of contagious complications of the site of sample and $2.7 \%$ of cytosteatonecrosis on 222 lipofillings 14, while Delay E brings back an infection of the site donor, 13 contagious complications in the breast, $3 \%$ of home of cytostéatonécrosis and a case of pneumothorax over 2350 lipofillings. $^{10}$ Contagious complications answer antibiotherapy well, cytostéatonécrosis can diminish spontaneously or being able to require an incision under local anesthesia. ${ }^{10-14}$ In a more recent study, Johns $\mathrm{N}$ et al bring back rare complications after the use of fatty transplant in mammary reconstruction immédiate. $^{20}$ In our experience, we did not notice all these complications, on the contrary we had a case of coetaneous necrosis of which we also thought to be linked of too superficial and excessive fasciotomy on an irradiated skin. ${ }^{10}$ Evolution was favorable after some weeks of local care and result was satisfactory after the sessions of lipofilling.

Still Delay E think that $30 \%$ volumes of transferred grease is reduced and the volume of the breast remains stable at the end of 3-4 months after intervention 10 and we share the same opinion because a month after intervention, we pointed out a loss of volume in the order of $30 \%$ in $50 \%$ and then the volume remains stable. Authors remind that the transferred grease keeps the memory of its place of origin that is if the patient slims down after intervention, she will lose a part of the benefit of intervention where from importance that the patient is in her weight of balance at the time of intervention. ${ }^{10,21,22}$

At the beginning, the risk of repetition of breast cancer was a subject of debate on the injection of grease in mammary reconstruction after surgery for breast cancer, especially in correction of the consequences of conservative treatments. ${ }^{3,10}$ Towards the end of $1980 \mathrm{~s}$, Bricoll and al offered the use of the fatty transfers in the breast, but the publications launched very virulent reactions of opposition because they thought that the 
injections of grease in the breast could procreate microcalcifications and cysts that can bother the detection of cancers and in 1987, the American ASPRS society declared itself disadvantageous to the use of the fatty transfer in the breast, then studies were led entraining a progressive lifting of debate..$^{3-10,23}$

Currently, many studies bring back the security of this technology. Debald $\mathrm{M}$ and al did not find recurrence among the effects of the lipofilling in their studies published in 2017. ${ }^{24}$ of The authors bring back the absence of repetition after lipofilling, on a length median of monitoring of 76.5 months after the lipofilling, Fertsch $\mathrm{S}$ and al did not notice repetition, as well as some authors but with a delay of shorter monitoring displayed over 36 months nevertheless others record a rate of local repetition in the order of $1.69 \% .{ }^{25-28}$ In our series, $62.57 \%$ cases benefited from monitorings of a length of more than a year with a medium length of monitoring which is of 13.94 months (1-25 month) and authors did not notice local repetition given that surveillance includes a clinical and radiological examination. Currently, all authors agree about the fact that the lipofilling is a technology simple, efficient and sure and part of the therapeutic armory in reconstruction mammary after surgery for breast cancer and we are also of this opinion. $3,10,24-28$

To assess the satisfaction of the patients, we used the questionnaire BREAST-Q which is an auto-questionnaire validated and intended specifically to quantify satisfaction and ease after mammary surgery. Since his creation in 2009, the questionnaire BREAST-Q (C) know an increasing use, with already 57 uses in publications classified on the basis of bibliographic data Pubmed $®$ between January 2009 and June 2014. Among these 57 articles, 10 were intended to describe or to assess the validity of the questionnaire, 8 were debates or answers of the author and 39 were clinical studies. ${ }^{8-29}$ It is for this reason that we chose him in its post surgical version to assess the aesthetic and psychological satisfaction of the women having benefited from the lipofilling in mammary reconstruction after surgery for a breast cancer.

During this study, authors fixed as satisfying the upper score in 60. A score of more than 60 was recorded in every domain in more than $90 \%$ cases. This situation is identical to those published where the authors bring back high rates of "very satisfied" and "satisfied" women on aesthetic and psychological plan after the reconstruction of their breast by lipofilling. ${ }^{13,19,30}$ These "satisfied" women tell they have a flexible «breast and of natural consistency» and significant benefits at the level of the zones of sample authors could nevertheless record 4 cases $(11.43 \%)$ of dissatisfaction in comparison with the aspect of their breast, $3(8.57 \%)$ women not satisfied in comparison with waiting's but it is patients who were only in their first session. Two $(5.72 \%)$ women have to leave because of pain, 4 patients could not confirm the impact of reconstruction on sexual activity.
The Breast $Q$ is an efficient tool to assess satisfaction after a mammary reconstruction, but its only disadvantage to our opinion and according to some authors it is that he does not allow a valuation globale. ${ }^{8}$ Generally, the women treated would recommend mammary reconstruction by lipofillng if advice is asked them.

\section{CONCLUSION}

Currently, mammary reconstruction makes integral part of the taking care of breast cancer. Used in complement or in exclusive, the lipofilling is one of the techniques used and rapidly developing in this taking care. Across this study, we could describe a simple, efficient technology, with little of scar and without risk of repetition. Next to his effectiveness and to his security, one of the advantages of the lipofilling is the aesthetic and psychological great satisfaction of the women with the feeling of credit «a flexible breast and of natural consistency. We think that mammary reconstruction by reinjection of grease is a technology which goes connaitre a big development. It is a new way of natural reconstruction at the mastectomies patients who wish, more and more a less aggressive surgical gesture with good result. With the evolution of the taking care of the cancers of breast, the lipofilling is going to constitute a major element to augment the rate by mammary autologue reconstruction.

\section{Funding: No funding sources \\ Conflict of interest: None declared \\ Ethical approval: Not required}

\section{REFERENCES}

1. Guizard AV, Tretarre B. Estimate of impact and of mortality by cancer in France of 1980 has 2005 . HCL, Inserm Invs Francim. 2008.

2. Arriagada R, The MG, Rochard F, Contesso G. Conservative treatment versus mastectomy in early breast cancer: patterns of failure with 15 years of follow-up dated. Institute Gustave-Roussy Breast Cancer Group. J Clin Oncol Off J Am Soc Clin Oncol. 1996;14(5):1558-64.

3. Mojallal A, Gebert L, Butcher F, Shipkov H. Transplant of adipose cloths in mammary reconstruction after surgery of breast cancer. In: Fitoussi A, Benoit C. Surgery of breast cancer and mammary reconstruction. 2nd ed. Elsevier Masson; 2017: 89-135.

4. Delay E, Guerid S. Fatty transfer in surgery of the breast. Surgical Technical EMC-plastic Surgery, Reconstructrice Aesthetic. 2017;12(4):1-12.

5. Zocchi ML, Zocchi L. Broad volume breast fat transfer: technical evolutions and safety aspects based one to 800 huts and 26 years of follow up. Euro J Plast Surg. 2017;40:367-82.

6. Cogliandro A, Barone M, Tena S, MarolliCoppola M, Persichetti P. The role of lipofilling after breast reconstruction: evaluation of outcomes and patient with 
Breast-Q satisfaction. Aesth Plast Surg. 2017;41:132531.

7. Morrow M, Li Y, Alderman AK. After mastectomy and patient perspectives one reconstruction decision making Access to breast reconstruction. JAMA Surg. 2014; 149:1015-21.

8. Lead T, Valuation multicentrique of the quality of life and of the satisfaction of the patients according to the questionnaire BREAST-Q after mammary reconstruction for cancer by rag of DIEP or rag of back big muscle. thesis of medicine: human medicine: Claret. 2014:118.

9. Quentin F, High authority of health. Reconstruction of the breast by cutanéo-fatty rag free from the abdomen, with vascular anastomose. Technology DIEP. 2011.

10. Couturaud B, Mojallal A, Veber M. Reconstruction by back big rag. In: Fitoussi A, Benoit C. Surgery of breast cancer and mammary reconstruction. 2nd edition. Elsevier Masson; 2017:201-260.

11. Mundy LR, Homa K, Klassen LF, Pusic AL, Kerrigan CL. Breast cancer and reconstruction: normative dated for interpreting the Breast-Q. Plast Reconstr Sur. 2017;139:1046e.

12. Mojallal A, Foyatier JL. Historical review of the employs of adipose tissue transfer in plastic explosive and reconstructive surgery. Ann Chir Plast Esthet. 2004;49(5):419-25.

13. Hoquoc C, Carrabin N, Meruta A, Piat JM, Delay E, Faure C. Lipofilling and breast cancer: where we are in 2015. J Gynécol Obstét Biol Repr. 2015;44(9):812-7.

14. Bayti T, Panouilleres M, Tropet Y, Bonnetain F, Pauchot J. Lipofilling in mammary reconstruction. Retrospective study of satisfaction and of quality of life regarding 68 patients. Ann Chir Plast Esthet. 2016;61(3):190-9.

15. Van Turnhout AA, Fuchs S, Brone LK, Nieumehuis EJC, Sluis WB. Surgical result and autologous fat cosmetic findings in grafting after breast conservation surgery and radiotherapy for breast cancer: a retrospective cohort study of 222 large grafting sessions in 109 patients. Aesth Plast Surg. 2017;41:1334-41.

16. Kasem A, Wazir U, Headon H, Mokbel K. Breast Lipo Filling: a review of current practice. Arch Plast Surg. 2015;42(2):126-30.

17. Ferraro GA, Francesco F, Tirino V. Effects of a new centrifugal method on fat cell viability for autologous fat grafting. Plastic Plast Surg. 2011;35:341-8.

18. Fabiocchi L, Semprini G, Cattin F, Dellachiesa L, Fogacci T. Expansion of Frisoni G. Reverse: a new technique of breast reconstruction with autologous tissue. J Plast Reconstr Aesthet Surg. 2017;70:1537-42.

19. Naidu NS. The role of lipopolysis after breast reconstruction: evaluation of patient satisfaction and results of Breast Q. Aesth Plast Surg. 2017;41:1332-3.
20. Quoc HC, Piat JM, Carrabin N, Meruta A, Faure C, Delay E. Mammary reconstruction exclusively by fat transfer and pre-expansion BRAVA: evaluation of efficacy on 45 cases. Ann Chir Plast Esthet. 2016;61(3):183-9.

21. Johns N, Fairbairn N, Track M, Ewing A, Tong L, Raine C. breast reconstruction and other Autologous using immediately liporempli extended latissimuus dorsi the beat. J Plast Reconstr Aesthet Surg. 2018;71(2):201-8.

22. Delay E, Delaporte T, Sinna R. Alternatives to breast prostheses. Ann Chir Plast Esthet. 2005;50:657-72.

23. Delay E. Lipomodeling of the reconstructed breast. In: Spear SE, eds. Breast surgery: principles. Philadelphia: Lippincott Williams and Wilkings; 2006: 930-46.

24. Bricoll M, Novack BH. Autologous transplant using liposuction techniques. Ann Plast Surg. 1987;18:327-9.

25. Debald M, Pech T, Kaiser C, Paik MD, Bruenagel WG, Kalff JC. lipo-filling effects after breast cancer surgery in post-radiation patients: a results analysis and algorithm proposal. Eur J Plast Surg. 2017;40(5):44754.

26. Fertsch S, Hagouan M, Munder B, Schulz T, AbuGhazaleh A, Schaberick J. The increased risk of recurrence was associated with some risk factors in breast cancer patients after the reconstruction of DIEPbeat and the lipopolysis: a corresponding cohort studies with 200 patients. Gland Surg. 2017;6(4):315-23.

27. Stumpf Centimeter, Biazus JV, Zucatto FSAE, Cericatto R, Cavalheiro JAC, Damin APS. Immediate reconstruction with the major fact of autologous grafting: influence in breast cancerregional recurrence. Reverend Colonel Bras Cir. 2017; 44 (2): 179-86.

28. Khan LR, Raine CR, Dixon JM. Immediate lipoplasty in breast conservation surgery. Eur J Surg Oncol. 2017; 43 (8): 1402-8.

29. Delay E, Guerid S, Meruta AC. Indications and controversies in lipoplombage for partial breast reconstruction. Clin Plast Surg. 2018;45(1):101-10.

30. Cogliandro A, Barone M, Tena S, Coppola MM, Persichetti P. The role of lipofilling after breast reconstruction: evaluation of outcomes and patient satisfaction with Breast-Q. Aesth Plast Surg. 2017;41:1325-31.

Cite this article as: Aimé RLN, Martial RA, Kamary RV, Lova A, Ibrahim H, Rousseau E, Andrianampanalinarivo HR. Mammary lipofiling seen to the hospital complex of Dax. Int J Reprod Contracept Obstet Gynecol 2019;8:2475-81. 